NBER WORKING PAPER SERIES

INNOVATION POLICY IN A NETWORKED WORLD

\author{
Olav Sorenson \\ Working Paper 23431 \\ http://www.nber.org/papers/w23431 \\ NATIONAL BUREAU OF ECONOMIC RESEARCH \\ 1050 Massachusetts Avenue \\ Cambridge, MA 02138 \\ May 2017
}

The Yale School of Management provided generous financial support for this research. I also with thank Josh Lerner, Yasin Ozcan, Scott Stern, and participants of the 2017 NBER Innovation Policy and Economics conference for useful comments on earlier versions of this paper. The views expressed herein are those of the author and do not necessarily reflect the views of the National Bureau of Economic Research.

NBER working papers are circulated for discussion and comment purposes. They have not been peer-reviewed or been subject to the review by the NBER Board of Directors that accompanies official NBER publications.

(C) 2017 by Olav Sorenson. All rights reserved. Short sections of text, not to exceed two paragraphs, may be quoted without explicit permission provided that full credit, including () notice, is given to the source. 
Innovation Policy in a Networked World

Olav Sorenson

NBER Working Paper No. 23431

May 2017

JEL No. O31,O32,Z13

\begin{abstract}
$\underline{\text { ABSTRACT }}$
Social relationships channel information, influence, and access to scarce resources. As a consequence, social networks - the patterns of these relationships across the members of a community - influence who comes up with important innovations, whether and how rapidly those innovations get adopted, and who has the ability to commercialize them. They therefore also affect the overall rate at which innovation occurs in the economy. This essay provides an introduction to and review of the research on social networks most relevant to innovation, with a particular focus on the earliest stages of the innovation process. It then discusses the likely consequences of a variety of policy interventions that could either reduce the importance of social relationships to innovation or alter the patterns of relationships in ways that might promote innovation.
\end{abstract}

Olav Sorenson

Yale School of Management

olav.sorenson@yale.edu 
The solving of the structure of DNA contains examples of many of the ways in which social relationships shape the process of innovation. It required the combination of ideas from a range of fields, from biology to mathematics and physics. Watson gained early access to the crystallography, a crucial piece of information, because he had met Wilkens at a conference and remained in contact with him. Crick and Watson, the most central individuals involved, moreover, have received most of the credit for the discovery, despite the near simultaneous determination of the structure of DNA by others and despite the involvement of Franklin and Wilkens. ${ }^{1}$ Social relationships played a role in determining both who first arrived at the discovery and who received attention for it.

Thinking about the world as an interconnected structure of relationships has diffused from its origins in anthropology and sociology to influence not just the social sciences but also the biological and physical sciences. This perspective importantly views the world as a set of points (often referred to as nodes or vertices), which might represent individuals or organizations, connected by a set of relationships (also called edges), which could reflect almost any sort of connection, such as a kinship tie or the movement of goods or ideas. Graphs of social networks, such as those depicted in Figure 1, appear regularly not just in academic papers but also in the popular press.

This perspective has provided a powerful lens for social scientists to study

\footnotetext{
${ }^{1}$ The Nobel Committee also named Wilkens to the prize with Crick and Watson. Franklin, however, had been ineligible because she died four years before the awarding of the prize.
} 
the importance of social structure for a variety of reasons. It has allowed researchers to define more rigorously what they mean by social positions. Being a broker, for example, has been defined as being the only path between two others - such as Beth in relation to Alex and Chris in Figure 1. More importantly, one can easily convert these graphs into matrices, allowing one to bring a large set of mathematical tools to the table. Topology - the study of the geometric properties of these graphs - has become central to large swaths of research.

Although social relationships influence many aspects of economic life and may have implications for multiple domains of public policy, they have particular relevance to policy related to innovation and entrepreneurship for at least two reasons. First and foremost, as the discovery of the structure of DNA highlights, these processes frequently require the combination of expertise or information distributed across individuals and organizations. Outcomes therefore depend on the joint choices of multiple actors, meaning that incentives and regulations oriented at the individual level often fail to yield the intended consequences.

Second, these processes involve a great deal of uncertainty. Inventors and entrepreneurs rarely have a good sense of whether their ideas will succeed. Funders, investors, potential collaborators and employees, and customers fare no better in assessing these odds. Given the difficulty of predicting the consequences of their choices, individuals in these situations often rely more on heuristics and gut feelings - such as whether they trust someone - than 
on rational calculations to guide their interactions.

Despite the importance of social relationships to the processes of innovation and entrepreneurship, however, innovation policy has given these issues little attention to date. That relative disregard stands in contrast to the substantial and growing awareness of the importance of understanding the ways in which policy interacts with the economics of innovation, particularly the incentives faced by individuals and organizations. Adopting a network perspective effectively opens the "black box" of innovation-moving from conceptualizing innovation as an investment, with particular costs and returns, to thinking of it as a process, potentially amenable to molding.

In the first section, I will review the ways in which social relationships and the patterns of these relationships, networks, have been found to influence the process of innovation and the commercialization of inventions. I have organized this research according to what has been thought to flow through these connections: information, influence, or scarce resources. In the second section, I then suggest some of the potential policy implications. These effects have relevance to one class of policies which could reduce the importance of social relationships to innovation and entrepreneurship, thereby mitigating the downsides of such effects. They also have relevance to another class of policies which could stimulate the creation of more of the most valuable kinds of social connections. 


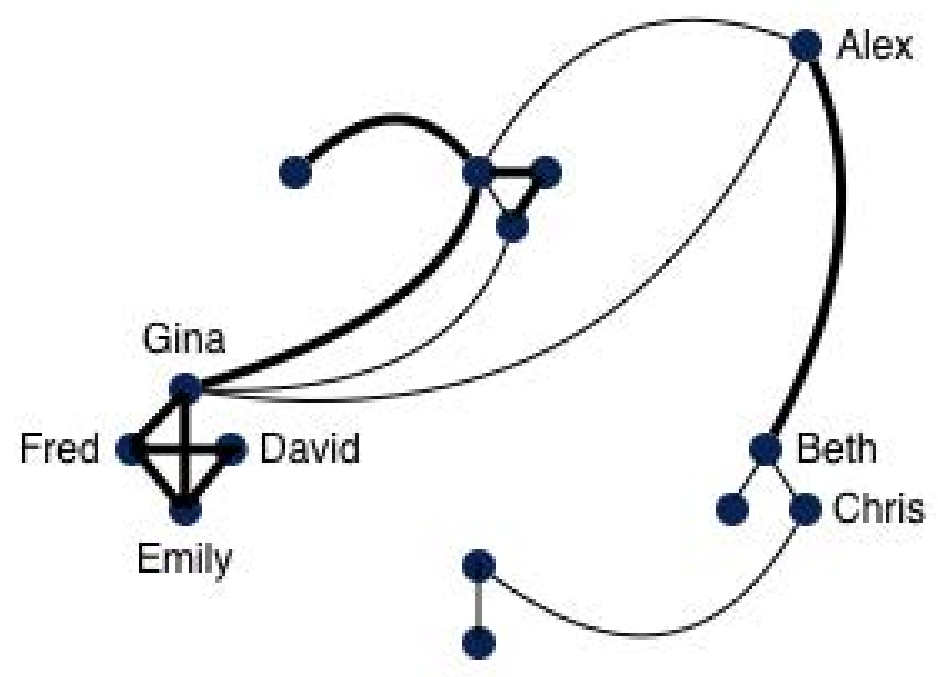

Figure 1: Stylized network

\section{Relationships and research}

One of the central issues in research from a social network perspective involves how one should define the nodes and the edges. Organizations or individuals have generally been the nodes in the research relevant to innovation. But what should constitute the edges?

From a theoretical point of view, researchers generally have acquaintances and friendships in mind, some form of social connection. Many of the early studies from this perspective therefore used "name generator" questions to measure these relationships, asking respondents with whom they discussed 
important matters (or some similar topic beyond casual conversation). But surveying individuals about their relationships has three notable disadvantages. It costs a lot; it gives the researcher only a cross-sectional view of the network, a snapshot in time; and it relies on the accurate recall and reporting of these relationships by respondents.

Research therefore has increasingly turned to focusing on connections captured in various ways in archival records. That has shifted research on social networks from what one has in mind theoretically - with whom does a person interact? - to an almost purely pragmatic definition of relationships - what can we measure? Instead of trying to trace the acquaintances and friendships that people accumulate over the course of their lives, researchers usually end up measuring discrete transactions or formal agreements. For example, much of the research on social networks in innovation has focused on collaboration networks, relationships established on the basis of (successful) co-authorship or co-invention, because one can capture these connections in patents and published papers.

In other research, geographic proximity has instead been used as a proxy for acquaintances and friendships. Both the odds of having a connection to someone and the frequency of interaction with that person decline with distance. All else equal, you're more likely to talk with someone down the hall than someone a few blocks away, and more apt to meet someone in the same city than someone in another state. The earliest studies established these patterns in terms of who people married (Bossard, 1932), but subsequent 
research has demonstrated that it holds true for everything from friendships to business associations (Festinger et al., 1950; Baker, 1984; Sorenson and Stuart, 2001). Tom Allen brought these ideas to research on innovation, demonstrating that individuals within a research facility interacted more frequently with those in nearby offices than with those in more distant ones (Allen, 1977).

In many ways, one might actually prefer the evidence based on studies of proximity. When one measures actual relationships, one must worry that the relationship reflects some attribute of the individual, perhaps being unusually gregarious or creative. Any apparent effects of these connections may therefore stem from the attributes that led to them rather than from the social network itself (Manski, 1993). By contrast, geographic proximity (and location) essentially provides information about the physical opportunities for interaction, something less obviously influenced by characteristics of the individuals involved (Samila and Sorenson, forthcoming).

Leaving aside issues of how one measures the connections, one can classify research on the effects of social networks in innovation and entrepreneurship according to what has been thought to flow through these relationships: Much of the research has focused on the idea that social relationships act as channels for the flow of information. Other studies have seen relationships as conveying social influence, what one might think of not as information per se but as how people interpret the information that they encounter. Yet other research has focused on the ways in which social relationships determine who 
has access to scarce resources, such as money and attention. Let me review the ideas behind each idea and some of the research on these effects relevant to the processes of innovation and entrepreneurship.

\section{Information flow}

Perhaps the most common way in which social networks have been thought to influence innovation and economic transactions has been as a channel for the flow of information. This idea, of course, depends on the assumption that one could not readily access the information through a public source, such as a journal or the Internet. But information may remain private for a variety

of reasons: It might involve tacit knowledge that even those in possession of it find difficult to write down. Imagine trying to describe how to hit a tennis serve. It might include knowledge that one would prefer only to reveal to trusted parties, such as gossip or a process innovation that provides one lab or researcher with an advantage over others.

But it might also reflect a failure on the part of the knowledge holder to recognize the importance of the information. This reason may have particular relevance to the process of innovation. In the course of their investigations, for example, researchers and inventors run many experiments that become intellectual dead ends. Thomas Edison famously quipped that "I have not failed. I have simply found 10,000 ways that won't work." Publication records, however, tend to focus on the successes, the things that worked. A huge store of valuable information about what not to do therefore resides pri- 
marily in the private memories and notes of researchers, potentially available to those connected to them.

Consistent with the idea that much relevant information remains private, studies have found strong evidence of the importance of social relationships to the flow of information. Perhaps the most common means of tracing these flows has been to examine citations. In one of the earliest studies of this sort, Jaffe et al. (1993) demonstrated that patents cite other patents invented in the same metropolitan area about three times as often as one would expect based on the geographic distribution of inventions of related technologies. ${ }^{2}$ More recent studies have tried to trace the effects of social relationships themselves. Singh (2005), for example, found that patents would more commonly cite as prior art earlier patents that had been invented by collaborators or by common collaborators ("friends-of-friends") of the inventor, even after accounting for the geographic proximity of the inventors and for shared organizational affiliations.

One prominent consequence of the fact that information flows through social relationships - combined with the fact that most relationships connect those in close proximity - has been that economic activity, particularly with respect to innovation, tends to cluster in space. This general notion has been

\footnotetext{
${ }^{2}$ Subsequent research suggests that this study may not have accounted sufficiently for the geographic distribution of inventive activity, the fact that some regions do more research on certain topics than others (Thompson and Fox-Kean, 2005). But the distribution of inventive activity itself may depend on information flow, so finding smaller distance effects after adjusting for this distribution may also simply demonstrate that inventors more commonly co-locate in technological areas where the flow of information depends more strongly on interpersonal interaction.
} 
around at least since Alfred Marshall, who in the late ninteenth century had already noted that in industrial clusters innovative ideas appeared to be in the air. It has nevertheless continued to shape beliefs about why innovation concentrates in certain regions (e.g., Krugman, 1991; Audretsch and Feldman, 1996).

Although the notion of being "in the air" might give the inaccurate impression that anyone located in a region could simply breathe in all of the ideas and information generated there, innovation and entrepreneurship within an industry do appear to occur at faster rates in regions with larger numbers of firms in the industry or in closely related ones (Sorenson and Audia, 2000; Porter, 2003). To the extent that social connections, which tend to localize within regions, provide access to valuable information, the geographic concentration of communities engaged in innovation in an area will lead to the faster flow of ideas, to fewer researchers duplicating each others' efforts, and therefore to a more efficient and productive community.

Another consequence of the fact that information flows through relationships - combined with the fact that innovation often results from the recombination of existing ideas and information - has been a focus on the importance of brokers and boundary spanners - those such as Beth in Figure 1 who bridge otherwise unconnected parties. Within a lab or small group, ideas and information may spread so quickly that everyone in the group essentially shares the same point of view. In Figure 1, David, Emily, Fred, and Gina would probably bring more similar ideas to the table than Chris 
and Emily would. By contrast, because those on opposite sides of social boundaries - organizations, subunits, or even academic fields - interact less frequently, they often have very different bases of information.

Two ideas have been central to the believed importance of these boundaryspanners. First, innovation frequently comes from the recombination of existing ideas (components) in novel ways. Second, many of these components have not already been recombined because the same individuals do not have expertise in, perhaps not even awareness of, all of them. Instead, that expertise exists only across two or more communities, whether the relevant communities denote teams, organizations, or academic fields. Many of the advances in bioinformatics, for example, have required the combination of an understanding of biology with expertise in preexisting ideas from computer science, mathematics, and statistics. Boundary spanners conduct information across these communities that would not otherwise interact.

Communities that have higher levels of interconnectedness - meaning that they have more boundary spanners - have accordingly been found to innovate more successfully. Breschi and Lenzi (2016), for example, reported that the density of collaboration among researchers in a metropolitan area correlates positively with its future production of patents. Samila and Sorenson (forthcoming), similarly, found that more integrated communities produced more patents. Inventions from these more integrated communities, moreover, involved more novel recombinations of components and appeared to have greater value and to apply to a wider range of applications. 
Boundary spanners themselves may also be unusually well situated to discover novel recombinations. Burt (2004), for example, found that individuals within a firm who had more relationships across social groups tended to have their ideas for business innovations rated higher. Fleming et al. (2007) similarly found that inventors who had collaborated with more unconnected others produced more novel inventions, in the sense of bringing together technological components not previously combined. de Vaan et al. (2015) reported that the designers of video games appeared particularly innovative when they bridged across intellectually-distant groups of developers.

At the individual level, however, the meaning of these results becomes less clear. People do not become boundary spanners purely by chance. Lee (2010), for example, found that boundary spanners in biotechnology had been high performers before they began to bridge intellectual communities. When he examined whether these individuals became more productive or more creative after they began to interact more broadly, he found little effect. But relatively few studies have used designs that would allow them to disentangle the effects of the individual from that of the position.

\section{Influence}

Another large set of studies has thought of social relationships as conduits

for social influence. Some of the earliest research of this sort examined the adoption of technology. In the 1930s, the introduction of hybrid corn seeds began to increase the yields that farmers could expect from an acre of land. 
But hybrid corn also had a cost: farmers had to purchase it from seed producers rather than using grain from the previous year as seed. Still, in less than five years, hybrid corn grew from a small fraction of plantings to more than $90 \%$ of them. Ryan and Gross (1943), in one of the first studies of the sort, conducted a survey to find out which farmers had adopted hybrid seeds. They found that more educated farmers with larger farms tended to adopt the hybrid seeds earlier. But they also found that farmers appeared to be much more influenced in their decisions by seeing a friend or neighbor adopt the technology than by reading about it in a farming magazine or hearing about it from a seed salesperson.

Lest one consider farmers less sophisticated than other potential technology users, another early study demonstrated similar patterns among physicians in deciding whether to prescribe a novel antibiotic. Coleman et al. (1957) surveyed physicians in a hospital to see whether they appeared susceptible to social influence in their prescribing behaviors and, if so, who influenced them the most. They found that central doctors - those with a large number of connections - who had a reputation for being early adopters appeared most influential to the prescribing practices of those around them. These insights may seem unsurprising today - they have become standard practice in the art of promotion - but their importance had not been widely appreciated at the time. Over the intervening 60 years, however, hundreds if not thousands of studies have documented these influence effects across a wide variety of products and practices (for reviews of this literature, see 
Strang and Soule, 1998; Rogers, 2003).

Why does social influence matter so much, even for products and practices where potential users have a wealth of objective information? At least three factors appear to come into play: The first concerns the perceived veracity of the information. Although these farmers and doctors could have obtained the same information from the representatives of the companies selling the seeds and drugs, those sources obviously have an incentive to mislead them to promote sales of the products. Even seemingly-independent sources of information could have conflicts of interest of which the potential adopters remain unaware. Magazines, for example, may receive advertising dollars from the manufacturers, giving them an incentive to publish favorable reviews. Even the authors of academic journal articles may have received money related to the products being assessed.

Individuals have greater confidence in the information coming from friends and colleagues for a variety of reasons. They probably have more information about the relationships that their contacts have with the companies providing the goods and services; they therefore have greater awareness of any potential conflicts of interest. Relationships with friends and colleagues also usually carry a degree of trust. Trust builds over time. It usually begins with one party putting itself at risk to the opportunism of the other, but where the cost of being betrayed is small. If the other party acts in a trustworthy manner, then the next test may involve something more meaningful. With each passed test, trust strengthens. Relationships also introduce a shadow of 
the future in information exchange. Friends and acquaintances presumably value the relationship either directly because they enjoy interacting with the individual or indirectly because they believe that they benefit from it. Since providing false information or bad advice would place that relationship in jeopardy, they should less likely do so.

The second factor stems contributing to social influence is the fact that individuals tend to perceive information that comes from friends and acquaintances as more relevant. To a large extent, that's sensible. People exhibit homophily - meaning that they tend to form and maintain relationships with those similar to themselves - on a surprising range of attributes, everything from race and gender to political persuasion (for a review, see McPherson et al., 2001). To the extent that these factors matter to whether adopting an innovation would prove valuable, people should place greater weight on the opinions and actions of those similar to them. But people often apply these heuristics also even when they would lead them astray.

The final factor behind social influence is the social desirability of doing something or of adopting a particular point of view. Ideas and information from close contacts may prove unusually influential because individuals want to copy their friends and acquaintances. Lab experiments, for example, have found that people tend to shift their opinions, even about objectively verifiable facts, towards the beliefs of those around them. People may therefore wish to adopt their friends' ideas simply to be more like them.

Friends and acquaintances vary, however, in the extent to which they are 
influential. In the study of drug diffusion, the most central physicians had the most sway over their peers (Coleman et al., 1957). Being central in a network, such as Alex in Figure 1 who has multiple connections to others who themselves have several connections, tends to signal high status. In other words, physicians paid more attention to and placed greater weight on the opinions of their high-status peers.

Robert K. Merton (1968) first highlighted the importance of the status effect in science, dubbing it the Matthew Effect (for the line in the book of Matthew in the Bible in which the rich get richer). As noted in describing the opening anecdote about the discovery of the structure of DNA, status can influence who receives credit for an idea, particularly in the case of team or simultaneous discovery. Because higher-status individuals have greater influence, it can also help to determine which ideas garner research attention. If a Nobel prize winner writes a paper, everyone in his or her field will read it; if someone peripheral does, they probably will not. Merton saw this attention effect as being functional - those of high status achieved their standing because of the quality of their past ideas, so one might expect them to have better-than-average future ideas.

But attention is a scarce good. Giving it to high-status individuals and organizations means potentially missing good ideas that come from more peripheral parts of the community or organization. Recent evidence, moreover, points to the potential downside of these status effects: Although distinguishing the effects of status from those of quality can prove challenging, Simcoe 
and Waguespack (2011) exploited an interesting pseudo-natural experiment to untangle this knot. They examined whether proposals for Internet standards got published based on the status of the authors of the proposal. Importantly, in some cases, the high status author ended up lumped into an "et al" abbreviation. While in other cases, they did not. They could therefore compare cases where authors of similar status either appeared or did not appear on the announcement. Using this approach, they found that roughly three-quarters of the effect of status appeared associated with the attention that the idea received, as opposed to its underlying quality. Attention and resources therefore may focus on high-status researchers even when the quality of their ideas does not warrant it.

Social influence can also have a second downside. The same social processes that promote the adoption of technologies can also produce fads and fashions, inefficient over-investment in some ideas. Individuals often assume that others have information that has not been shared with them. If I see a colleague using a tablet, for instance, I might reasonably believe that the person has a better sense of the utility of the device than I do and accordingly raise my own perception of its value (and consequently also my odds of buying one). But, of course, my colleague may have different preferences than I do or may even regret purchasing the device.

Although research on fads and fashions in innovation remains limited, almost anyone in academia recognizes that topics and approaches become "hot" for periods of time. In research on management, for example, the 
late-1990s witnessed a wave of interest in complexity theory, a branch of mathematics examining deterministic systems that produce behavior which appears quasi-random. More recently, researchers in economic sociology have become enamored with social categories, the idea that classification influences the ways in which buyers and sellers perceive products, people, and organizations and therefore with whom they will interact and how much they will pay. After a flurry of articles, however, complexity theory has been relegated to a small, niche at the periphery of the management literature. Something similar may happen to the economic sociology of categories. One might therefore question the extent to which this allocation of attention has been optimal.

\section{Access to resources}

The final thing that has been thought to pass through social relationships has been access to scarce resources, such as the funds or equipment required to do research. One might think of information as a resource as well, but here I have in mind what an economist might call "rivalrous" goods -in other words, resources of finite quantity, where giving it to one party usually implies not giving it to another. By contrast, in principle at least, one could distribute a particular idea or piece of information to everyone.

Gaining access to scarce resources has been particularly important to innovation in terms of determining who can commercialize an idea or start a company. For example, much of the funding for the commercialization of technology comes in the form of venture capital. Although venture capi- 
talists actively seek entrepreneurs and innovators, they tend to rely heavily on their social relationships in identifying and evaluating these opportunities. Because entrepreneurs and innovators have an incentive to overstate their own abilities and the value of their ideas, venture capitalists depend on trusted third parties as sources of insight into the acumen of entrepreneurs and the promise of their innovations. These relationships, however, remain largely local both in social and in physical space. Venture capitalists therefore primarily invest in entrepreneurs located less than 60 miles from their headquarters (Sorenson and Stuart, 2001).

This fact can have negative consequences for those not connected to venture capitalists, either directly or through friends or acquaintances. Entrepreneurs and inventors from regions that lack a local venture capital community find it difficult to finance their ideas. This difficulty, moreover, can extend even to those who simply travel in different social circles. Women and minorities, for example, rarely receive funding from venture capitalists, who are almost all white men.

The importance of social relationships to founding firms, however, extends to resources beyond simply money. Entrepreneurs, for example, frequently rely on their relationships to recruit early employees (Ruef, 2010). Connections to others may also help them find their first customers, as well as their suppliers and their other partners. Startups therefore have the strongest survival chances and prospects for profitability when their founders have deep social connections to the regions in which they reside (Dahl and Sorenson, 
2012).

Interestingly, the patterns of relationships that maximize the amount of information and influence that an individual might have do not also optimize the odds of that person assembling the resources needed to found a firm. Whereas access to information and influencing others depends on exposure, being able to convince others to entrust you with valuable resources often requires being connected to those people not just incidentally but also through common friends. Someone like Gina in Figure 1 then probably has the best network for becoming an entrepreneur-being connected to a tightknit group that she can count on for support and resources while simultaneously having some exposure to ideas and information from outside that group. Or, these combinations of relational configurations can arise through collaboration. Aven and Hillman (forthcoming) in their historical study of Russia, for instance, found that the most successful entrepreneurial teams appeared to combine individuals who spanned boundaries with those who belonged to tight-knit social circles.

\section{Innovation policy}

Given the ways in which social networks shape the flow of information, influence, and resources, how might a recognition of these facts affect our understanding of policies for promoting innovation and entrepreneurship? I see two main themes: The first involves policies that would reduce the impor- 
tance of social relationships to innovation and entrepreneurship. The second considers policies that might alter the network itself, in ways conducive to innovation. In both cases, the importance of considering the effects of social relationships in innovation policy probably matters most to basic and relatively early-stage research, where the process of innovation involves the most uncertainty.

\section{Creating commons and opening access}

Although most of the research on social networks portrays them in a positive light, the restricted access to information and resources described above has a flip side: exclusion Think the old boy's club. This tendency for exclusion suggests that simply allocating more money or resources to a research area might do little to stimulate innovation, particularly if funding committees and grant reviewers end up channeling those resources to the usual suspects, high-status researchers, and friends and colleagues of those distributing the funds. By contrast, policy interventions that involve reducing the importance of social relationships for access to resources and information - by creating commons - can often promote innovation.

Publication represents one of the oldest and most important means of creating an information commons. Writing up the results of research and placing it in the public record does indeed appear to allow a wider range of individuals to build on earlier innovations. Lee Fleming and I, for exam-

ple, estimated the extent to which publication might influence the flow of 
information related to patenting (Sorenson and Fleming, 2004). We examined the geographic localization of citations to patents that built on ideas published in academic journals relative to those that built only on earlier patents. Inventions referencing published ideas exhibited less than half of the geographic localization of those that did not. In other words, follow-on inventions to ideas that had been published came from a much more dispersed set of places. This effect, moreover, appeared particularly pronounced in the first few years following the initial invention, when presumably access to information about inventions not based on published research depended almost entirely on close social connections.

Open access journals and repositories may reduce the barriers to accessing information even further. A small cottage industry has compared the citations to articles published with open access relative to those behind paywalls. Although the magnitude of the effects vary by field, on average, these studies have found that open access publications receive more citations (e.g., Lawrence, 2001; Evans and Reimer, 2009). In the interest of ensuring that everyone can read about the results of the research that they support, European funding agencies and universities have therefore begun to require their researchers to publish in open access journals or to pay for article-level open access in journals behind paywalls.

Although publication and, more recently, the availability of open access journals and research repositories have broadened access to research results, the flow of certain sorts of information remains largely locked in social circles. 
Consider non-results and negative findings. These failed innovations carry a great deal of information value, as suggested above. But researchers rarely publish them. They may tell their friends and close colleagues about them, allowing those researchers to avoid these intellectual dead-ends. But the larger community often remains unaware of these issues.

Worse than simply not being aware of the research done by others, the published record itself can become misleading. In many fields, such as medicine, researchers commonly study small samples. Small samples can arise because of the rarity of the condition being examined or the cost of doing the research. Regardless of the reason, small samples mean that the findings tend to vary a great deal from one sample (experiment) to the next. When one combines this variation with a tendency to publish only positive or significant results, the publication record for some effect - such as the efficacy of a drug or therapy in treating some disease - might appear positive even if no real relationship exists. In a meta-analysis of meta-analyses, Fanelli et al. (2017) found that small sample sizes commonly produced patterns in the published record of overly large, and often inconsistent, effects.

Although we do not have a good sense of how common these issues are, some recent replication studies suggest that they may be widespread. Amgen, for example, reported being able to reproduce the results of only 6 out of 53 studies that they had deemed landmarks in cancer research (Begley and Ellis, 2012). In an evaluation of important studies in experimental economics, Camerer et al. (2016) could replicate just over half of the original results. 
One would therefore ideally want the publication commons to include these non-results. Encouraging researchers to publish them, however, will not prove easy. Journals, particularly the more prominent ones, rarely want to publish papers based on non-results. As intellectual dead-ends, papers reporting them will not receive many citations, the currency of the realm for academic journals. The inability to report this research in prominent journals, in turn, means that researchers being considered for funding and promotion receive little credit for any effort put into this public good. It becomes a pure cost with little prospect of glory or reward.

Preregistration review offers one intriguing idea here. In this model, researchers submit their study design and journals essentially commit to publishing the resulting paper regardless of the results found. Not only does this model allow researchers to publish non-results but also it largely removes their incentives to focus on analyses that find only positive results. Psychologists have been at the forefront of this idea but one could imagine porting it to other fields, particularly those where empirical research primarily involves lab experiments. If funding agencies wanted to promote the dissemination of non-results - the experiments that did not find the anticipated effects - they could require the projects that they fund to adopt this approach to research and publication.

Another interesting approach might involve trying to lower dramatically the costs associated with reporting results. At the moment, researchers must generally write an article with an introduction, a literature review, a long 
description of the methods, and a discussion, even to report minor or insignificant results. But imagine a world in which one would just submit some details of the study design and the results to a website, something like an indexed and search-able wikipedia of failed ideas and experiments.

Perhaps the solution would even come in the form of software that researchers could use as a lab notebook to track their research privately, with the option to publish it in "raw" format at any point (i.e. without additional details). One might worry about the quality of the research or the veracity of the information being reported. But, given that these submissions would probably contribute little to the financial rewards or career progression of those submitting, the incentives to game the system seem limited. Better yet, perhaps the careful documentation of the procedures could even become a sort of portfolio that people would use in job applications and in promotion evaluations, much as github has become not just a repository for code but also a means for programmers to advertise and document their expertise and experience. But, as a public good, the development and support for such a platform would probably need to come from an organization with the resources and credibility to sustain it and to maintain its neutrality.

One could also consider creating commons for important inputs beyond just information. Many steps of the research process require materials of different sorts, from biological entities to computer programs. Consider, for example, two researchers studying the influenza virus. This virus, like most biological entities, comes in many strains. A treatment that might have an 
effect on one strain might not on another. But unless researchers have samples of the exact entity used in another laboratory, they can find it difficult to determine whether they have been studying the same thing.

Once again, accessing these resources has historically depended on social connections, contacting the initial researcher to get the data or to obtain a sample of the material. Not only does this fact limit the number of people who could build on the initial research, but also it may bias the research record if the original researchers restrict access to those they see as favorable to their findings.

In medicine and the life sciences, biological resource centers (BRCs) have therefore come to play an important role in providing researchers with samples of the exact entities used in published research. Furman and Stern (2011) estimated that the deposit of an entity in a BRC increased the extent to which future research built on the published papers using that entity by more than $60 \%$. Funding agencies interested in forwarding research in the biological sciences might therefore consider supporting these centers financially. But the value of BRCs depends entirely on researchers depositing biological samples to them. Funding sources truly interested in promoting the use of these centers and more reliable biological research might then further require the deposit in BRCs of any entities developed for use in the research that they fund to ensure that these deposits get made.

More broadly, a recent strand of research suggests that providing public access to the data underlying published research could accelerate the ad- 
vancement of and innovation in nearly all fields. Piwowar and Vision (2013), for example, found that articles that deposited their data in a public repository received roughly $10 \%$ more citations than those that did not, even after accounting for a number of characteristics of the research and the researchers.

Policy interventions oriented at creating commons, however, primarily involve ways of expanding access to non-rivalrous goods. Providing more widespread access to scarce resources, such as money, people, and equipment, could also stimulate innovation. But what kinds of interventions might help to distribute scarce resources more broadly? The most obvious ones involve simply targeting individuals and groups that have not enjoyed access to these resources. Special selection processes, for example, for grants for those who have not previously been funded can clearly spread funding across a more diverse set of researchers. Systems that specify minimum allocations of funds to various regions or to particular research institutions and universities can also help to distribute resources more broadly.

A slightly less obvious solution would entail going to more extreme lengths to shield the identity of those in need of resources from those responsible for allocating them. Grant applications, for example, remain an area where the referees and funding committees are aware of the identities of the applicants. Leaving aside potential issues of outright discrimination, people tend to consider ideas from their friends and acquaintances to be better than those from strangers of objectively-similar ability. Being aware of the applicants' identities may therefore give an advantage to applicants with prior connections 
to those allocating the funds. Sandström and Hällsten (2008), for example, found that grant applicants who shared an institutional affiliation with someone on the reviewing committee received substantially higher scores on their proposals - and consequently had higher odds of being funded - even after holding constant the quality of the applications.

An even more novel approach might focus on diversifying the individuals responsible for allocating resources. Exclusion most commonly occurs when two factors coincide: (i) social relationships sort strongly on some characteristic, and (ii) the resources in question have been unequally distributed on that same characteristic. Venture capitalists, for example, are overwhelmingly white men with degrees from elite institutions. It should perhaps not surprise us then that women, minorities, and those from less-privileged backgrounds rarely receive venture capital backing for their ventures. But distributing the decisions across a broader swath of society could go a long way toward eliminating these issues. Organizations interested in supporting innovation from a broader base of applicants might then first diversify the characteristics of those staffing their hiring and selection committees.

\section{Promoting interaction}

Creating commons and expanding access nevertheless have limits in terms of their ability ot stimulate innovation. Although these approaches can help to disseminate relatively discrete pieces of information and artifacts useful to research, such as computer programs and biological entities, they can do little 
to create the kinds of connections that often prove essential in breakthrough innovation and in fundamental research, bringing together deep insights or expertise from more than one domain. They also have less to contribute to entrepreneurship and to the commercialization of innovations.

Policymakers therefore might also want to influence the structure of networks themselves to promote innovation and entrepreneurship. But, given that these underlying connections represent friendships and acquaintances, that poses a challenge. One cannot simply declare by fiat that an individual should have a particular set of friends. Even direct incentives to encourage interaction may feel somewhat taboo.

Policies designed to promote collaboration can also run awry. The European Union, for example, has run some grant programs that require applicants to involve researchers from multiple member nations. One of the problems with such programs, however, stems from two of the factors noted above: trust and homophily. In the absence of severe restrictions on who these collaborations can involve, researchers tend to select those they trust and those similar to them, almost uniformly those they already know. These programs then simply reinforce the existing social network rather than altering it in ways that might promote innovation. Worse yet, to the extent that they promote joint research among acquaintances who had not already been collaborating, they likely lead to low-potential projects.

What managers and policymakers can do, however, is to create opportunities for forming relationships. They can ensure that two people meet. Where 
it goes from there, however, will depend on the parties involved. In that sense, it provides only a blunt policy instrument, as many of these meetings will not result in collaborations or even in stable connections. That unfortunately also means that the cost-benefit ratios of some of these interventions remain poorly understood because little systematic research has been done on the rate at which chance meetings result in relationships.

We can, however, guess that these attempts to create opportunities for forming friendships will have the greatest value when they bring together individuals who would not normally meet. Since the two most important factors in determining the structure of social networks have been geography and social similarity, that generally means trying to bring people from disparate backgrounds - different bases of expertise, different experiences closer together in physical space.

Conferences provide one of the most obvious opportunities for connecting individuals across regions. In a sense, they also have relatively low cost, as they only require people to travel for a few days. But does such a short engagement actually allow for the formation of ties or the transfer of valuable information? We do not really know.

Anecdotes abound of collaborations and important connections that began at conferences. Watson apparently first encountered Wilkens at a conference in Italy. I first met four of my own coauthors at conferences (for evidence from surveys of mathematitians and physicists, see Liberman and Wolf, 1997). Some studies moreover have found strong correlations between confer- 
ence attendance and research productivity among academics (e.g., Rappa and Debackere, 1992; Prpić, 2000). But attending academic conferences involves two forms of selection. Individuals must choose to attend the conference, and many conferences only select the best papers submitted to them. Whether conference attendance promotes the production of ideas or whether productive people have more opportunities to participate in conferences therefore remains unknown. ${ }^{3}$

Research has found that somewhat longer stays do appear sufficient to create valuable connections. Choudhury (in press), for example, studied the short-term sojourns of Indian research personnel to headquarters in the United States. Although these visits averaged less than three months, he found that they had noticeable effects, increasing the number of patents subsequently invented by the researchers who made these visits. At least in his context, however, these effects appeared to stem from the fact that the stays allowed the employees to gain additional financial support for their research rather than from the transfer of relevant knowledge during their visits. More encouragingly, among Spanish academics participating in visits to international institutions, stays on the order of several months had a high rate of resulting in co-authorships with faculty at the host institutions (Andujar et al., 2015).

\footnotetext{
${ }^{3}$ Fleming and Waguespack (2007) suggest a way forward for estimating these effects in future research. For conferences that change locations from year to year, distance to the individual appears a strong predictor for the probability of attendance. It therefore could potentially serve as a source of exogenous variation in conference attendance.
} 
Although these activities can certainly promote the kinds of relationships that produce more, and more valuable, inventions, research has not really answered many of the questions relevant to designing the most effective policies. We have almost no evidence on how to the duration of an interaction influences the odds of transferring useful information or of maintaining a social connection.

We also have little sense of how best to design these interactions. Consider, for example, the optimal size of a conference. Larger conferences conceptually allow for more chance meetings, one might therefore expect them to yield more novel connections. But in social situations, people have a tendency to gravitate to those they already know - they catch up with old friends and acquaintances rather than meeting new ones. The probability of any individual having a set of existing contacts at the conference rises simply by chance with the size of the conference. Smaller conferences - perhaps something in the 20 to 50 participant range - where few of the attendees have had prior interactions, may therefore prove more valuable to creating connections.

Conferences and visits can bridge long distances, but one can also think usefully about stimulating interaction at a much more local level. For those involved in overseeing physical research facilities, for example, the design of buildings and the assignment of individuals to offices or lab benches would appear to offer many opportunities for encouraging interaction. Interestingly, Kabo (in press) found that the geography of office spaces predicts 
interpersonal interaction even more strongly than homophily (social similarity). Office configurations, therefore, probably offer a powerful means for shaping the formation of social relationships.

Numerous studies have found that these micro-level physical locations matter. Allen (1977), for example, interestingly noted that eight vertical feet (being on a different floor) had as much of an effect on the probability of interaction as one hundred horizontal feet. More recently, Catalini (2012) found that moving labs at a university to be adjacent to one another more than tripled the odds of collaboration between the researchers in them. Liu (2016), similarly, has not only found that location within a lab influences the interactions between researchers in a biotechnology firm but also that those sitting closer to other research groups more commonly become boundary spanners between those groups.

These studies would appear to point to clear policy implications in cases where the manager has a good understanding of which interactions might prove valuable. But locating two individuals or research groups in close proximity to each other also implies locating others at greater distance. The assignment of individuals to offices or locations therefore involves a variety of trade-offs. But essentially no research has been done on trying to understand these trade-offs and how best to weigh them in arriving at an optimal allocation of spaces.

The ideal spatial arrangement of a building might not even entail a static allocation of offices. Once formed, relationships tend to endure, at least for 
a while. People will go out of their way to meet with friends, for coffee, for lunch, or just for a chat. Creating the largest number of possible connections between individuals with varied expertise and knowledge may therefore require reassigning individuals to desks or offices on a regular basis.

The configuration of the space itself also probably matters. More compact spaces, those with a smaller ratio of circumference to area, such as circles and squares, allow for more individuals to reside in close proximity to one another. Indeed, in the two cases that he studied, Kabo et al. (2015) found that the more compact building layout had more cross-group interaction than the one with a more linear layout.

Research relevant to the social engineering of relationships, both within and across organizations, nevertheless remains in its infancy. We need more research designed with an eye to practical problems and involving interventions. Moving this agenda forward will require experimentation on the part of managers and policymakers. Hopefully, the results of those experiments, whether successful or failed, will also be shared, such that the community can gain a better understanding of the opportunities for shaping the structure of social networks.

Let me close by noting that the importance of connections to entrepreneurship and innovation also means that many seemingly-unrelated policies could have implications for these processes. Consider one of the less obvious ones: Factors that reduce the mobility of people, either across regions or across companies, will also tend to reduce the number of boundary-spanning con- 
nections and concomitantly the innovativeness of firms and regions. When people move, they retain many of their old connections while forming new ones, effectively becoming boundary spanners.

This fact raises some concerns. Mobility has been declining in the United States. Americans move less across regions now than they have at any other point in the last 30 years (Molloy et al., 2011). They also move less frequently across employers, though that trend appears largely due to the immobility of mothers (Hollister and Smith, 2014). America may therefore be losing some of its innovative capacity. Potential policy responses to those issues fall beyond the scope of this essay but they would undoubtedly involve a much wider range of levers than usually considered relevant to innovation policy.

\section{References}

Allen, Thomas. 1977. Managing the Flow of Technology. Cambridge, MA: MIT Press.

Andujar, Ines, Carolina Canibano, and Ana Fernandez-Zubieta. 2015. "International stays abroad, collaborations and the return of Spanish researchers." Science Technology and Society 20:322-348.

Audretsch, David B. and Maryann P. Feldman. 1996. "R \& D spillovers and the geography of innovation and production." American Economic Review $86: 630-640$. 
Aven, Brandy and Henning Hillman. forthcoming. "Structural role complementarity in entrepreneurial teams." Management Science .

Baker, Wayne E. 1984. "The social structure of a national securities market." American Journal of Sociology 89:775-811.

Begley, C. Glenn and Lee M. Ellis. 2012. "Drug development: Raise standards for preclinical cancer research." Nature 483:531-533.

Bossard, James S. 1932. "Residential propinquity as a factor in marriage selection." American Journal of Sociology 38:219-224.

Breschi, Stefano and Camilla Lenzi. 2016. "Co-invention networks and inventive productivity in US cities." Journal of Urban Economics 92:66-75.

Burt, Ronald S. 2004. "Structural holes and good ideas." American Journal of Sociology 110:349-399.

Camerer, Colin F., Anna Dreber, Eskil Forsell, Teck-Hua Ho, Jurgen Huber, Magnus Johannesson, Michael Kirchler, Johan Almenberg, Adam Altmejd, Taisan Chan, Emma Heikensten, Felix Holzmeister, Taisuke Imai, Siri Isaksson, Gideon Nave, Thomas Pfeiffer, Michael Razen, and Hang Wu. 2016. "Evaluating replicability of laboratory experiments in economics." Science 351:1433-1436.

Catalini, Christian. 2012. "Microgeography and the direction of inventive activity." Rotman School of Management Working Paper No. 2126890. 
Choudhury, Prithwiraj. in press. "Innovation outcomes in a distributed organization: Intra-firm mobility and access to resources." Organization Science .

Coleman, James, Elihu Katz, and Herbert Menzel. 1957. "The diffusion of an innovation among physicians." Sociometry 20:253-270.

Dahl, Michael S. and Olav Sorenson. 2012. "Home sweet home? Entrepreneurs' location choices and the performance of their ventures." Management Science 58:1059-1071.

de Vaan, Mathijs, David Stark, and Balazs Vedres. 2015. "Game changer: The topology of creativity." American Journal of Sociology 120:1144-194.

Evans, James A. and Jacob Reimer. 2009. "Open access and global participation in science." Science 323:1025.

Fanelli, Daniele, Rodrigo Costas, and John P. A. Ioannidis. 2017. "Metaassessment of bias in science." Proceedings of the National Academy of Sciences 114:3714-3719.

Festinger, Leon, Stanley Schachter, and Kurt W. Back. 1950. Social pressures in informal groups. Stanford, CA: Stanford University Press.

Fleming, Lee, Santiago Mingo, and David Chen. 2007. "Collaborative brokerage, generative creativity, and creative success." Administrative Science Quarterly 52:443-475. 
Fleming, Lee and David M. Waguespack. 2007. "Brokerage, boundary spanning, and leadership in open innovation communities." Organization Science 18:165-180.

Furman, Jeffrey L. and Scott Stern. 2011. "Climbing atop the shoulders of giants: The impact of institutions on cumulative research." American Economic Review 101:1933-1963.

Hollister, Matissa N. and Kristin E. Smith. 2014. "Unmasking the conflicting trends in job tenure by gender in the United States, 1983-2008." American Sociological Review 79:159-181.

Jaffe, Adam, Manuel Trajtenberg, and Rebecca Henderson. 1993. "Geographic localization of knowledge spillovers as evidenced by patent citations." Quarterly Journal of Economics 108:577-598.

Kabo, Felichism. in press. "A model of potential encounters in the workplace: The relationships of homophily, spatial distance, organizational structure, and perceived networks." Environment and Behavior .

Kabo, Felichism, Yongha Hwang, Margaret Levenstein, and Jason OwenSmith. 2015. "Shared paths to the lab: a sociospatial network analysis of collaboration." Environment and Behavior 47:57-84.

Krugman, Paul. 1991. Geography and Trade. Cambridge, MA: MIT Press.

Lawrence, Steve. 2001. "Online or invisible?" Nature 411:521. 
Lee, Jeongsik "Jay". 2010. "Heterogeneity, brokerage, and innovative performace: Endogenous formation of collaborative inventor networks." Organization Science 21:804-822.

Liberman, Sofía and Kurt Bernardo Wolf. 1997. "The flow of knowledge: Scientific contacts in formal meetings." Social Networks 19:271-283.

Liu, Chris. 2016. "Brokerage by design: Formal structure, geography and crosscutting ties." Working paper, University of Toronto.

Manski, Charles F. 1993. "Identification of endogenous social effects: The reflection problem." Review of Economic Studies 60:531-542.

McPherson, Miller, Lynn Smith-Lovin, and James M. Cook. 2001. "Birds of a feather: Homophily in social networks." Annual Review of Sociology $27: 415-444$.

Merton, Robert K. 1968. "The Matthew Effect in Science." Science 159:5663.

Molloy, Raven, Christopher L. Smith, and Abigail Wozniak. 2011. "Internal migration in the United States." Journal of Economic Perspectives 25:173196.

Piwowar, Heather A. and Todd J. Vision. 2013. "Data reuse and the open data citation advantage." PeerJ 1:e175. 
Porter, Michael E. 2003. "The economic performance of regions." Regional Studies 37:549-578.

Prpić, Katarina. 2000. "The publication productivity of young scientists: An empirical study." Scientometrics 49:453-490.

Rappa, Michael A. and Koenraad Debackere. 1992. "Technological communities and the diffusion of knowledge." RESD Management 22:209-220.

Rogers, Everett M. 2003. Diffusion of Innovations. New York: Free Press, 5th edition.

Ruef, Martin. 2010. The Entrepreneurial Group. Princeton, NJ: Princeton University Press.

Ryan, Bryce and Neil Gross. 1943. "The diffusion of hybrid seed corn in two Iowa communities." Rural Sociology 8:15-24.

Samila, Sampsa and Olav Sorenson. forthcoming. "Community and capital in entrepreneurship and economic growth." American Sociological Review

Sandström, Ulf and Martin Hällsten. 2008. "Persistent nepotism in peerreview." Scientometrics 74:175-189.

Simcoe, Timothy S. and Dave M. Waguespack. 2011. "Status, quality, and attention: What's in a (missing) name?" Management Science 57:274290. 
Singh, Jasjit. 2005. "Collaborative networks as determinants of knowledge diffusion patterns." Management Science 51:756-770.

Sorenson, Olav and Pino G. Audia. 2000. "The social structure of entrepreneurial activity: Geographic concentration of footwear production in the United States, 1940-1989." American Journal of Sociology 106:424462.

Sorenson, Olav and Lee Fleming. 2004. "Science and the diffusion of knowledge." Research Policy 33:1615-1634.

Sorenson, Olav and Toby E. Stuart. 2001. "Syndication networks and the spatial distribution of venture capital investments." American Journal of Sociology 106:1546-1588.

Strang, David and Sarah A. Soule. 1998. "Diffusion in organizations and social movements: From hybrid corn to poison pills." Annual Review of Sociology 24:265-290.

Thompson, Peter and Melanie Fox-Kean. 2005. "Patent citations and the geography of knowledge spillovers: A reassessment." American Economic Review 95:450-460. 